
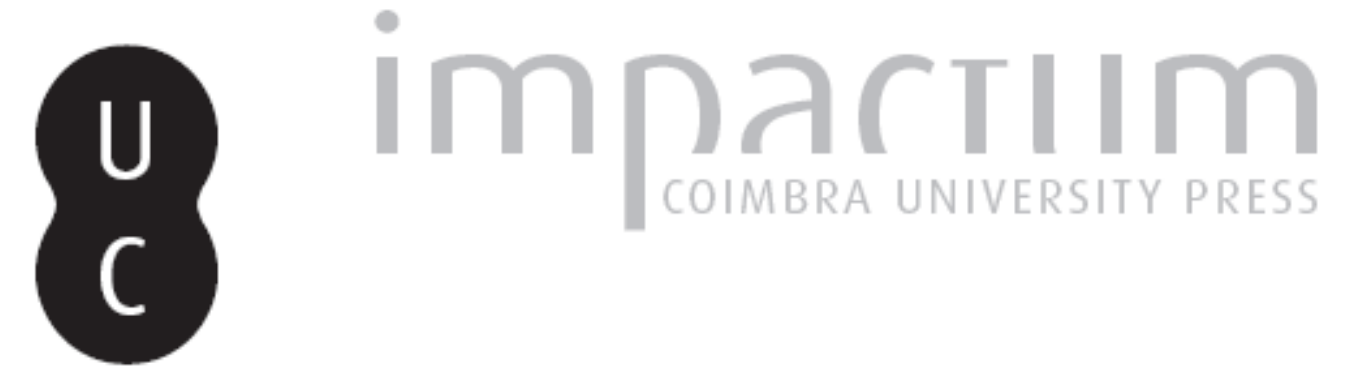

\title{
A loucura de Orlando
}

Autor(es): $\quad$ Santagata, Marco

Publicado por: Imprensa da Universidade de Coimbra

URL persistente:

URl:http://hdl.handle.net/10316.2/42605

DOI:

DOI:https://doi.org/10.14195/0870-8584_3_2

Accessed : $\quad$ 26-Apr-2023 12:08:01

A navegação consulta e descarregamento dos títulos inseridos nas Bibliotecas Digitais UC Digitalis, UC Pombalina e UC Impactum, pressupõem a aceitação plena e sem reservas dos Termos e Condições de Uso destas Bibliotecas Digitais, disponíveis em https://digitalis.uc.pt/pt-pt/termos.

Conforme exposto nos referidos Termos e Condições de Uso, o descarregamento de títulos de acesso restrito requer uma licença válida de autorização devendo o utilizador aceder ao(s) documento(s) a partir de um endereço de IP da instituição detentora da supramencionada licença.

Ao utilizador é apenas permitido o descarregamento para uso pessoal, pelo que o emprego do(s) título(s) descarregado(s) para outro fim, designadamente comercial, carece de autorização do respetivo autor ou editor da obra.

Na medida em que todas as obras da UC Digitalis se encontram protegidas pelo Código do Direito de Autor e Direitos Conexos e demais legislação aplicável, toda a cópia, parcial ou total, deste documento, nos casos em que é legalmente admitida, deverá conter ou fazer-se acompanhar por este aviso.

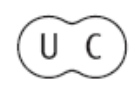




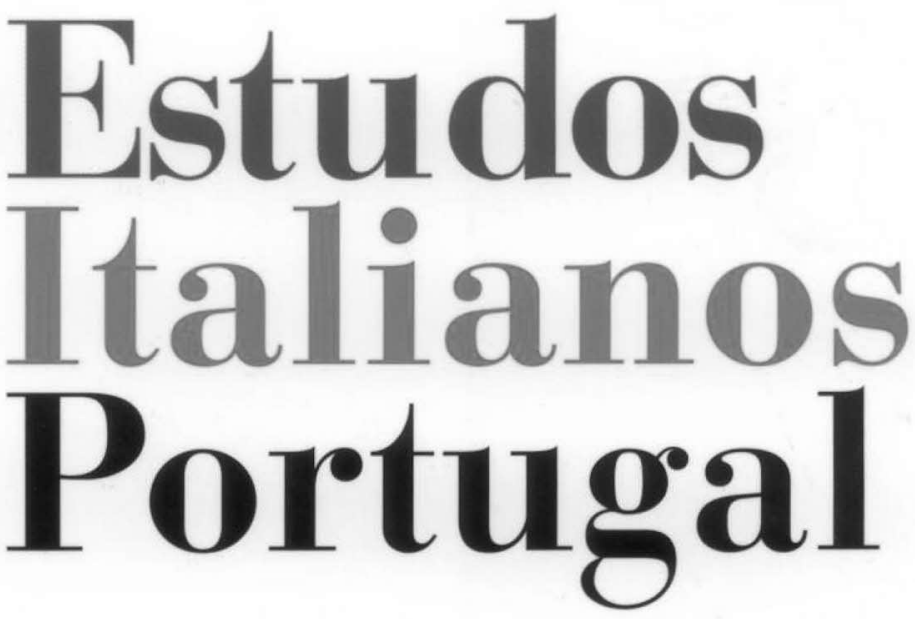

Instituto

Italiano

de Cultura

de Lisboa

Nova Série

$\mathrm{N}^{\circ} 3$

2008 


\section{A LOUCURA DE ORLANDO}

Marco Santagata ${ }^{\star}$

1. ORLANDO FURIOSO, publicado pela primeira vez no ano de 1516, em quarenta cantos; pela segunda, sem alterações relevantes, em 1521; e, por fim, em 1532, com quarenta e seis cantos, apresenta-se como uma continuação de Orlando innamorato ou Innamoramento di Orlando de Matteo Maria Boiardo, cuja elaboração tinha sido interrompida. A ideia não era peregrina: o sucesso do poema de Boiardo, na verdade, tinha sido tal que, ao longo das duas primeiras décadas do século XVI, foram numerosas as continuações que dele se escreveram (a mais conhecida das quais se deve ao véneto Niccolò Degli Agostini, que entre 1505 e 1524 publicou, nada mais, nada menos, do que três outros livros, a acrescentar aos três de Boiardo). Mas se os continuadores do poema de Boiardo até o título da sua obra retomavam, movidos por objectivos comerciais, Ariosto nunca cita o seu predecessor. De facto, apesar de a ligação temática existente entre os dois poemas ser profunda, o Furioso é tão inovador que dissipa do horizonte dos seus leitores o livro de Boiardo, colocando-se

* Professor da Universidade de Pisa. De entre os numerosos cargos que ocupa, contam-se o de Presidente honorário de ICON (Italian Culture on the Net), membro da Comissão Nacional Italiana da UNESCO e membro da Commissione Nazionale per la Promozione della Cultura Italiana do Ministério dos Negócios Estrangeiros. É autor de fundamentais estudos sobre Petrarca, Leopardi, Pascoli, D’Annunzio e sobre o lirismo e o bucolismo do Renascimento. Tradução de Rita Marnoto.

Est.Ital.Port., n.s., 3, 2008: 19-30 
a si mesmo, com prepotência, no vértice do género romance de cavalaria.

A personagem de Orlando exemplifica algumas das novidades ariostescas. Boiardo tinha violado a imagem secular do paladino casto e inteiramento votado aos seus deveres de cavaleiro, convertendo-o num súbdito de Amor que se esquecia do seu papel, numa perene procura do objecto de desejo (Angelica), sempre fugidio. Ariosto vai mais além, e daquele enamorado louco, como se costuma dizer, faz, literalmente, um louco por amor. O Orlando enamorado de Boiardo tinha-se emancipado, de facto, do cliché da tradição, mas nem por isso conquistara um estatuto autónomo de personagem. De uma escravidão a deveres e honra, tinha passado a uma servidão, não tanto a amor, quanto à máquina narrativa que o tema amoroso pusera em marcha. Agia mais como actante narrativo, funcional a uma história de imprevisíveis aventuras, do que como personagem em função da qual a história se ia construindo. O Orlando furioso de Ariosto, pelo contrário, assume uma fisionomia credível de personagem. Entenda-se bem, não personagem de um moderno romance burguês, ao qual se aplica a convenção de que deve ser dotado de uma vida sua, autónoma, extraliterária, sempre parcialmente representada pelo romance que lhe dá acolhimento. Por outras palavras, de personagem tomada de empréstimo à vida pela literatura.

Não é este o caso de Orlando. Orlando, e a observação é válida para grande parte das personagens do Furioso, nunca deixa ninguém esquecer-se de que é pura invenção, dotado, efectivamente, de uma outra vida, exterior ao romance específico, mas sempre confinada a livros e contos. Orlando, assim sendo, age como personagem puramente literária, nascida da literatura, só concebível na sua esfera, e, ao mesmo tempo, produz a sensação de ser uma personagem credível, como aqueles modernos que pretendem ter nascido da vida e da realidade. 
2. No canto XVIII de Orlando furioso, Medoro, um soldado sarraceno ainda adolescente, acompanhado pelo amigo Cloridano, leva a cabo uma expedição nocturna para recuperar o corpo do seu Rei, Dardinello, que caíra em combate, mas a empresa falha. Cloridano morre e Medoro fica ferido. Encontra-o Angelica, rainha do Catai, que tem pena dele, e o socorre. Leva-o para a cabana de um pastor, onde, graças aos seus desvelos, fica curado. Entretanto, Angelica, que tinha desprezado o amor dos mais nobres e valorosos guerreiros, de entre eles Orlando, enamora-se perdidamente pelo sarraceno, que não era mais do que um humilde soldado de infantaria, e permite-lhe que colha la prima rosa. Casam e passam a lua-de-mel com o pastor. Vão vagueando por lugares ali à volta, e gravam os seus nomes, enlaçados, nos troncos das árvores e em pedras. Antes de ir embora, Angelica oferece ao pastor, para o recompensar da hospitalidade recebida, uma pulseira cravejada de pedras preciosas. Durante a viagem para Barcelona, onde esperam poder embarcar para o Oriente, deparam com um nom pazzo, "che, come porco, di loto e di guazzo/tutto era brutto e volto e petto e schene" (XIX 42). Esse ser selvagem é Orlando, irreconhecível, em virtude da loucura que dele se tinha apoderado. Tudo isto sucede nos cantos XVIII e XIX. Como e por que razão Orlando perdeu o juízo, é contado mais adiante, no canto XXIII.

O paladino anda a vaguear há dois dias, à procura de um cavaleiro sarraceno, Mandricardo, o qual, quando com ele travava um duelo pela posse da espada Durlindana, tinha sido arrastado pelo cavalo, sem freios. Vai ter a um rio de águas cristalinas, por entre margens floridas. Está calor. Aproxima-se, para se refrescar. Não sabe que aquele lugar tinha sido teatro dos amores de Angelica e Medoro. Vê a gravação dos seus nomes, nos troncos das árvores (XXIII 102-103). Entretanto, enquanto se procura convencer a si próprio de que Medoro é um nome fictício usado por Angelica para 
esconder a identidade do homem que ela verdadeiramente ama, isto é, ele próprio, chega a uma gruta. E aqui, as suas ilusões sofrem um duro golpe, ao ler o poema escrito em árabe por Medoro, a celebrar a felicidade e o prazer dos seus amores (XXIII 106-112). O pobre Orlando fica num estado que nem chorar lhe permite, tamanha é a sua angústia. Todavia, ainda não se rende à evidência. Agarra-se à ideia de que alguém quererá manchar o nome de Angelica, e matá-lo de ciúmes. A noite está prestes a cair, e, nessa vã esperança, vai até à cabana do pastor. Será o pastor a dar-lhe a última machadada (XXIII 117-124). Está tão deprimido, que se atira para o catre, sem comer, mas não consegue cair no sono. O pastor, ao vê-lo em tal estado, para o animar, não encontra melhor expediente do que o de lhe contar a história dos dois amantes que ali tinham estado. Orlando ouve. Não cabe em si de amargurado. Pega no cavalo e nas armas, e vai pelo campo fora. Todo se entrega a lágrimas e lamentos. Sente que é a sombra de si próprio, o fantasma de um Orlando defunto: "Non son, non sono io quel che paio in viso:/quel ch'era Orlando è morto et è sotterra/[...]/Io son lo spirto suo da lui diviso" (XXIII 128). Durante o dia, volta à gruta onde se encontrava gravado o epigrama de Medoro (XXIII 129-135).

3. É então que o vemos enlouquecer. Entretanto, damo-nos conta de que não estamos a assistir a uma crise que surge de improviso, a um dos tantos episódios imotivados e surpreendentes que o género romance espalha, ao avançar livremente ao longo do fio da sua história e das suas digressões. O leitor já tinha sido preparado para esta cena, e não só porque Orlando, louco, já tinha aparecido, sob a irreconhecível aparência de um selvagem, no canto XIX, mas, sobretudo, porque os pressupostos narrativos e, por assim dizer, clínicos, desta cena colocada no preciso centro do poema, já tinham sido fixados num dos primeiros cantos, o VIII. 
E esta é uma outra novidade do modo de narrar de Ariosto. Não só adopta a técnica narrativa do entrelacement, ou seja, da multiplicação de fios narrativos entre si cruzados, e da procura, a quête, ou seja, da aventura, mas, além disso, usa-as em estreita relação uma com a outra. A suspensão e a procastinação narrativa são a causa fundamental que entrava o bom fim da procura, e esta, sempre instigada pela tentativa de satisfazer um desejo, torna-se fonte da qual podem jorrar e onde se podem cruzar as sequências narrativas. A narração ariostesca, portanto, apesar de aparentemente casual, obedece na realidade a uma lógica profunda: mostrar como é o desejo de despoletar as acções, e como as acções nunca podem satisfazer esse desejo. Trata-se de uma lógica que confere a um livro, o qual se apresenta, porém, como romance, uma ordem e uma estrutura que o aproximam das construções ordenadas dos poemas.

Orlando faz a sua primeira aparição no canto VIII: encontramo-lo na cama, sem dormir, angustiado pela perda de Angelica, tendo escapado à guarda de Namo, a quem Carlo a tinha confiado. Lamenta-se, desafogando a sua dor e os seus medos. Mais do que tudo, teme ser defraudado da sua flor, a virgindade de Angelica: se fosse colto e guasto por outrem, só lhe restaria matar-se: "Oh infelice! oh misero! che voglio/se non morir, se 'l mio bel fior colto hanno?" (VIII 78). Por fim, adormece, mas durante o sono sonha, e o sonho transforma-se em pesadelo. Sonha, de facto, estar, com Angelica, numa belíssima verde riva, coberta de flores, e deleitar-se com ela ("Sentia il maggior piacer, la maggior festa/che sentir possa alcun felice amante", VIII 81), quando uma tempestade, de improviso, destrói aquele jardim. No meio do turbilhão, Angelica desaparece. Orlando ouve-a invocar ajuda, mas não a pode socorrer. Uma voz misteriosa grita-lhe que nunca mais a irá ver: "Non sperar più gioirne in terra mai" (VIII 83). Acorda logo, e decide abandonar Paris cercada, os seus companheiros, o tio Imperador, e ir à procura de Angelica. E este o 
começo da quête, da indagação que irá desembocar na tragédia do canto XXIII. O desejo amoroso é mais potente do que qualquer outro sentimento, mas está destinado à frustração e à conversão em loucura. Na verdade, Orlando comporta-se como os loucos, desde o início: não distingue sonho e realidade ("Senza pensar che sian l'imagin false/quando per tema o per disio si sogna", VIII 84). Leva o sonho à letra, e deixa-se guiar pelo erro. Ora, veremos que é sobre o levar à letra que é construída boa parte do episódio da loucura.

São ténues os confins entre sonho e loucura, entre verdade e erro, tanto é que Ariosto inicia a história que conduzirá à loucura com um sonho, e, no final do romance, representa a recuperação do juízo de Orlando como o despertar de um longo pesadelo (XXXIX 58). Também esta correspondência de extremos mostra a sábia orquestração que organiza a aparente desordem da história.

4. No canto XXIII, Orlando, vagueando sem rumo (a errância fisica é metáfora do erro moral), chega a um locus amoenus (semelhante ao do sonho) repleto de sinais da passagem de Angelica, mas também repleto de provas do facto de que aquilo que ele mais temia tinha acontecido: a mulher que amava tinha-se oferecido, livremente, e segundo parecia com plena satisfação, a um outro. Orlando procura repetidamente auto-enganar-se, mas, por fim, tem de acreditar na realidade. E nesse mesmo momento, sai da realidade. Uma longa tradição filosófica e literária (retomada e difundida, em poesia, por Francesco Petrarca) interpretava o amor como uma doença da alma, e em casos mais graves também do corpo, caracterizada pela alienação. O sujeito perde o domínio de si e torna-se escravo do seu desejo. As partes invertem-se: o objecto amoroso, que não pode ser possuído, subjuga o sujeito do desejo. O modo como Ariosto representa a alienação mental leva ao extremo a tradicional dependência do outro, por parte do sujeito enamorado. 
A trajectória descrita por Orlando leva à perda da identidade e à anulação do sujeito. Todavia, não é a circunstância de Angelica ter fugido a desencadear a crise: que o objecto de desejo fuja, que se negue, desde a Dafne de Ovídio à Laura de Petrarca, é absolutamente normal, no quadro do código amoroso ocidental, e não, em particular, no de corte. E como Orlando é um cavaleiro, é a esse código que se deve fazer referência. A desencadear a Loucura, encontra-se o facto de Angelica, ao escolher dar-se livremente a Medoro, se ter transformado, de objecto passivo de desejo, em sujeito autónomo. Para tornar ainda mais ofensivo o seu comportamento, Ariosto leva-a a escolher um simples soldado, de origem humilde. Dentro daquele universo conceptual e comportamental, a identidade do homem enamorado era assegurada pelo carácter fixo dos papéis: activo, apesar de destinado à frustração, o masculino; totalmente passivo, o feminino. A inversão desse esquema não pode deixar de provocar uma crise de identidade no sujeito que a suporta. Hoje, diríamos que a de Orlando é uma crise paroxística de narcisismo ferido. A anulação de si nega a realidade e, sobretudo, a existência do rival. Orlando liberta-se das armas, que são o sinal distintivo primário de um cavaleiro, e espalha-as pelo bosque (XXIII 132-133), tornando-se irreconhecível, mesmo aos seus próprios olhos: "Non son, non sono io quel che paio in viso:/quel ch'era Orlando è morto et è sotterra" (XXIII 128). Com o seu Eu, morreu também o seu nome. Em termos modernos, também neste caso, poderíamos falar de esquizofrenia, caracterizada, precisamente, pela fragmentação e pela alienação do Eu. Aliás, os gestos que Orlando leva a cabo, depois de ter perdido o juízo, reentram, globalmente, no comportamento patológico do esquizofrénico: alterna um activismo hipercinético e, além do mais, desprovido de orientação ("pel bosco errò tutta la notte il conte", XXIII 129), com estados de catatonia ("afflitto e stanco al fin cade nell'erba/e ficca gli occhi al cielo, e non fa motto", 
XXIII 132). Não se alimenta, não dorme, desnuda-se e mostra-se na sua natureza insípida, cobre-se de porcaria, berra, e uiva. Em suma, Orlando não perde só os traços distintivos do paladino, mas também os do homem. O Eu ferido no seu narcisismo tem necessidade de reparação, de auto-afirmação. Orlando abocanha tudo o que encontra, sem distinção, e destrói, indiferentemente, todas as coisas que encontra pela frente. Transforma-se numa espécie de turbilhão vivo, e lança-se contra os sinais da injúria recebida.

É como se materializasse, em si próprio, a tempestade do sonho inicial. Como aquela, também a sua loucura destrutiva anula o locus amoenus.

5. O percurso patológico da personagem, desenhado com uma tal coerência psicológica que pode ser analisado através das categorias da moderna ciência psiquiátrica, enriquece-se de ulteriores significações, a que aludi anteriormente, se interpretado sobre o pano de fundo dos códigos e das convenções literárias típicas do discurso amoroso da época de Ariosto. A inversão dos papéis tradicionais, com efeito, fala por si: põe em relevo o facto de a interpretação tradicional do amor como perda de si, e portanto como alienação, apesar de partilhada por Ariosto (e assim o veremos), esconder um dado ainda mais dramático, quer dizer, a possibilidade de que, a andar perdido, poderá ser o próprio objecto de desejo. Com a sua traição, que o é só do ponto de vista de Orlando, é como se Angelica tivesse insinuado um princípio de realidade no universo convencional da literatura amorosa. Universo portador de uma sua verdade, bem entendido, mas de uma verdade limitada. Basta carregar no botão do imaginário amoroso poético, parece dizer Ariosto, para fazer emergir o seu núcleo mais dramático, que não é domesticável: noutros termos, para transformar, partindo dos mesmos pressupostos, uma insânia amorosa, sentida como dependência do outro, numa loucura desencadeada pela perda do 
outro. Nesta operação, é como se Orlando e Ariosto tivessem dividido as tarefas entre si, cada um no seu sector. Orlando, enquanto personagem, leva à letra os sonhos, e refugia-se na alienação, quando está perante a realidade; Ariosto, enquanto autor, leva à letra o sistema metafórico dominante na linguagem da literatura e do amor. Séculos de poesia petrarquista não tinham lamentado a condição do poeta enamorado, dividido dentro das suas próprias entranhas? Pois bem, quando Orlando exclama: "Io son lo spirto suo da lui diviso" (XXIII 128), isto é, a sombra daquele Orlando que è morto e sotterra, não designa, metaforicamente, uma condição de sofrimento psicológico, mas denota a condição clínica, portanto não metafórica, do desdobramento esquizofrénico. Os apaixonados, em poesia, não têm sono nem apetite, têm medo e esperanças, são inquietos e distraídos. Exasperadas tais condições até ao paroxismo, tem-se o comportamento de uma pessoa nas margens da loucura.

Ariosto não opera só como autor escondido. Desdobra-se, intervindo na primeira pessoa, como autor-personagem. Fá-lo sobretudo nos prólogos, mas não desdenha fazer ouvir a sua voz também dentro da narração. É uma voz que tem um tom prevalentemente irónico. Dentro da história, uma voz autobiográfica intervém para comentar a envergadura da dor que transforma Orlando em pedra, ao confrontar-se com o que escreveu Medoro: "Credete a chi n'ha fatto esperimento,/che questo è 'l duol che tutti gli altri passa" (XXIII 112). A mesma instância autobiográfica domina o prólogo do canto XXIV, um prólogo que serve de ponte entre a crise que leva Orlando à loucura e as extraordinárias e desarrazoadas acções que leva a cabo, naquele estado. Em ambos os casos, o tom tende a amortecer o dramatismo da situação. Nem todos os enamorados ficam frenéticos e tolos como Orlando, diz o prólogo, contudo, todos são considerados loucos, porque amor é insânia (XXIV 1). 
Os enamorados, continua na estância seguinte, deviam ser presos com cadeias: "a chi in amor s'invecchia, oltr'ogni pena/si convengono i ceppi e la catena” (XXIV 2). Aliás, também o autor do poema devia ser preso, e reconhece-o. Num momento de lucidez, ousa dizer estas coisas, bem sabendo que se encontra afectado até à medula, ele próprio, pelo mesmo mal. A ironia dissolve quer estas afirmações, quer os ângulos trágicos do episódio que as engloba. Ariosto logo trata de explicitar o horizonte cultural que circunscreve a sua exasperada representação da loucura amorosa, citando as duas autoridades máximas do discurso amoroso quinhentista. A definição de amor como perda de si ("che per altri voler, perder se stesso") é tirada à letra de uma canção do diálogo Gli Asolani (1505) de Pietro Bembo ("che per cercar altrui perdo me stesso", I xxx 52). A representação de si próprio como mau mestre ("Ben mi potria dir: - Frate, tu vai/l'altrui mostrando, e non vedi il tuo fallo") decalca a chave de um soneto de Francesco Petrarca ("Ben si può dire a me : Frate, tu vai/mostrando altrui la via, dove sovente/fosti smarrito, et or se' più che mai", $R v f$ 99, 12-14). Se o carácter excepcional da experiência de Orlando mostra os limites de uma concepção de amor dolorosa, mas que desconhece a verdadeira tragédia, o recurso à experiência autobiográfica reafirma o núcleo de verdade que subjaz àquela concepção, hoje adulterada, e transformada em algo quase insignificante pelo abuso que dela fez a tradição literária.

Todo o episódio parece desenrolar-se, então, através da dupla vertente da tragédia da personagem (que por vezes pode assumir vestes tragicómicas aos olhos dos leitores) e da comédia daquele que escreve e comenta (e que pode deixar entrever a angústia que vai nos bastidores). Esquizofrenia da personagem e supremo controle do autor integram-se e completam-se. 
6. A duplicidade, de resto, parece ser o denominador comum de toda a operação ariostesca. Ariosto joga, e ao fazê-lo lança raios de luz sobre o coração e o comportamento dos humanos. Fantasia, e, vagueando entre mundos imaginários, reproduz os enredos e os labirintos da realidade. Uma realidade que já não se identifica com a História, apesar de, muitas vezes, o narrador reenviar para a história e para os episódios da crónica, em relato directo. O processo classicístico de fazer literatura através da literatura, com o Furioso, chegou a um dos seus cúmulos: as vicissitudes dos cavaleiros de Ariosto não só se apresentam como continuação das que foram contadas num outro livro, como se inscrevem, além disso, num universo que é inteiramente literário. O Orlando de Ariosto, à semelhança do que acontecia com os Orlandos de Boiardo e de Pulci, não encarna valores historicamente determinados e não transmite modelos ou códigos comportamentais. Orlando é filho de uma tradição. Tanto ele, como o seu mundo, são convencionais. Essa tradição é o universo de realidade com o qual se confronta a fantasia ariostesca, que é, de facto, fantástica, mas não totalmente livre. Nesta obra, as adaptações e as rupturas relativamente à tradição verificam-se, e são perceptíveis, da mesma maneira que o são as adaptações e as rupturas implicadas por uma história realista, relativamente à realidade. Seria possível falar de metaliteratura, que pode significar distanciamento da história, mas não distanciamento da realidade. A história, sob a forma de crónica cortesã, era o trampolim a partir do qual se erguia em alto voo o classicismo do Poliziano das Stanze, aliás, logo se esquecendo do sítio donde tinha descolado; a história, sob a forma de experiência pessoal e de casta, era o pressuposto visado, de forma críptica e alusiva, pelo classicismo de Sannazaro. Em suma, tanto para um, como para o outro, era como se a literatura tivesse reservas em se apresentar como discurso absolutamente autónomo e auto-suficiente. O discurso de segundo grau de Ariosto, pelo con- 
trário, não procura pontos de partida ou pontos de chegada na crónica ou na experiência biográfica do autor. Crónica e autobiografia são matéria de um jogo mais vasto. Fazer literatura com a literatura desembocou, para Ariosto, numa visão realística, que não é mimética, do que está fora do texto (à Boccaccio), nem requer a integração do texto e do outro (à Dante), mas que, na sua auto-suficiência, reproduz ritmos, sentimentos, casos acidentais, aspirações e frustrações da vida. No microcosmo de cavalaria, mora uma realidade segunda, na qual aquela realidade primária se pode pontualmente espelhar. 